\title{
Regulation of Nitric Oxide by Cigarette Smoke in Airway Cells
}

\author{
Jia Liu ${ }^{1,2}$, Jun Wang ${ }^{3}$, Ah Siew Sim³, Nitin Mohan ${ }^{1,2}$, Sharron Chow ${ }^{4}$, Deborah H. Yates ${ }^{5}$, \\ Xingli Wang ${ }^{6}$, Paul S. Thomas ${ }^{1,2,4}$ \\ ${ }^{1}$ Prince of Wales Clinical School, Faculty of Medicine, University of New South Wales, Sydney, Australia \\ ${ }^{2}$ Department of Respiratory Medicine, Prince of Wales Hospital, Sydney, Australia \\ ${ }^{3}$ Cardiovascular Genetics Laboratory, Prince of Wales Hospital, Sydney, Australia \\ ${ }^{4}$ School of Medical Sciences, Faculty of Medicine, University of New South Wales, Sydney, Australia \\ ${ }^{5}$ Department of Thoracic Medicine, St. Vincent's Hospital, Sydney, Australia \\ ${ }^{6}$ Division of Cardiothoracic Surgery, Texas Heart Institute at St. Luke's Episcopal Hospital, \\ Baylor College of Medicine, Houston, USA \\ Email: paul.thomas@unsw.edu.au
}

Received November 3, 2011; revised December 13, 2011; accepted December 23, 2011

\begin{abstract}
Background and Objectives: Exhaled nitric oxide (NO) is decreased by smoking while oxides of nitrogen such as nitrites/nitrates $\left(\mathrm{NO}_{\mathrm{x}}\right)$ are increased. It was hypothesised that in vitro cigarette smoke extract (CSE) would either inhibit NO generation by increasing the NO synthase inhibitor, NG, NG-dimethyl-L-arginine (ADMA) or increase $\mathrm{NO}_{\mathrm{x}}$ levels via an oxidation pathway, which in turn could be inhibited by the antioxidant N-acetylcysteine NAC. Methods: Transformed airway cells (A549) were cultured with control medium, 1.0\% CSE in culture medium, or $0.8 \mathrm{mM}$ NAC with $1.0 \%$ CSE. Baseline L-arginine, $\mathrm{NO}_{\mathrm{x}}$ and ADMA levels were measured in the media. Conditioned media were then sampled at 1hour, 6 hours, 24 hours, 48 hours and 72 hours after incubation. Results: CSE induced significantly higher $\mathrm{NO}_{\mathrm{x}}$ levels (mean (SD) peak increase of $135.8(126.6) \%$ after incubation for 6 hours $(\mathrm{p}<0.0005)$ ). NAC pre-treatment partially reversed this effect to $35.6(21.4) \%$ at 6 hours $(\mathrm{p}=0.009)$. ADMA levels were significantly higher in the CSE conditioned media compared with control media $(\mathrm{p}=0.02)$ while NAC pre-treatment did not affect ADMA levels. Conclusions: CSE increased $\mathrm{NO}_{\mathrm{x}}$ which was partially reversed by NAC pre-treatment. ADMA levels were also increased after CSE exposure, suggesting that it activates the NO pathway via oxidative-stress while inhibition probably occurs via both ADMA and NOS.
\end{abstract}

Keywords: Airway; Cigarette; Nitric Oxide; Nitric Oxide Synthase; N-Acetylcysteine; NG; NG-Dimethyl-L-Arginine

\section{Introduction}

Smoking is known to decrease nitric oxide (NO) production but the mechanism is unknown [1]. One possible group of intermediaries implicated in the alteration in NO are the methylarginines. Asymmetric methylarginines are endogenous analogues of arginine, and include NG-monomethyl-L-arginine (L-NMMA) and NG, NGdimethyl-L-arginine (asymmetric dimethylarginine, ADMA). It has been established that these analogues inhibit the activity of nitric oxide synthase (NOS), presumably by competitive antagonism at the binding site for L-arginine [2-4]. Thus, these molecules are capable of decreasing NOS-related nitric oxide (NO) production, and have been proved to participate in a variety of physiological and pathological processes $[5,6]$.

Both L-NMMA and ADMA are detectable in plasma, but ADMA concentrations are approximately 10 times greater than that of L-NMMA [4]. ADMA was first identified in human urine in 1970 and has since been recognised as an inhibitor of NOS which may contribute to endothelial dysfunction $[4,7,8]$. Elevated ADMA levels in plasma have been shown to be associated with chronic renal failure, hypertension, chronic hypoxia-induced pulmonary hypertension, acute coronary syndromes, heart failure, stroke, alcoholic cirrhosis and Alzheimer's disease [4,9-17]. Smoking has been reported to be associated with increased plasma ADMA levels, although this has not been consistent $[18,19]$.

Exhaled nitric oxide is a highly reproducible marker of inflammation in the airways, and can be detected in expired breath. It is elevated in asthmatic patients, and may be useful for monitoring asthmatic airway inflammation $[20,21]$. Other markers of airway inflammation are nitrites and nitrates $\left(\mathrm{NO}_{\mathrm{x}}\right)$, the products of nitric oxide metabolism, and these oxides of nitrogen can be detected in 
exhaled breath condensate $(\mathrm{EBC}) . \mathrm{NO}_{\mathrm{x}}$ levels are raised in the exhaled breath condensate (EBC) of smokers and in patients with asthma and community-acquired pneumonia [22-25]. Although $\mathrm{NO}_{\mathrm{x}}$ levels in the $\mathrm{EBC}$ of smokers is elevated in comparison with normal subjects, exhaled NO is reduced [24,26,27].

Smoking decreases exhaled NO levels, but the mechanism is unknown. The possible pathways include: 1) cigarette smoking increases ADMA levels, thus suppressing NO production; 2 ) cigarette smoking could increase $\mathrm{NO}_{\mathrm{x}}$ levels via the oxidative stress pathway which in turn inhibits NO production by negative feedback; 3 ) cigarette smoking could increase $\mathrm{NO}_{\mathrm{x}}$ levels directly in $\mathrm{EBC}$ by donating oxides of nitrogen such as $\mathrm{NO}_{2} \cdot$ and $\mathrm{NO}_{3} \cdot$, and again these inhibit NO production by negative feedback $[24,28]$. To explore the mechanism behind the cigarette smoking altering NO metabolism, this in vitro study was conducted.

The respiratory tract is lined by airway epithelial cells (AEC), which are not only a physical barrier, but also play a crucial role in pulmonary host defense mechanisms. AEC produce pro-inflammatory cytokines and $\mathrm{NO}$, and NO release from AEC can be decreased by glucocorticosteroids (GCS) [29,30]. Also, NO production in AEC has been demonstrated to be inhibited by cigarette smoke extract (CSE) in a dose dependent manner, and the effect of CSE on $\mathrm{NO}_{\mathrm{x}}$ is shown to be inhibited by Nacetylcysteine (NAC) [1]. The mechanism is, however, not fully understood.

NAC, an acetylated precursor of the amino acid Lcysteine, is able to reduce the viscosity and elasticity of mucus by reducing disulphide bonds, and it has been used as a mucolytic for more than 30 years [31]. In addition to its clinical use as a mucolytic, NAC has also been used for treatment of acetaminophen-induced hepatotoxicity as well as for heavy metal poisoning. NAC contains a sulfhydryl ( $\mathrm{SH})$ group and also acts as a free radical scavenger in common with other thiol-containing compounds. Recently, there has been increasing interest in the finding that NAC has some beneficial effects in diseases involving oxidative stress, including heart disease, cancer and cigarette smoking [32,33]. Animal studies have established that a large dose of NAC is capable of inhibiting cigarette smoke-induced epithelial thickening in rat models [34,35].

It was hypothesised that CSE would either inhibit NO generation by increasing ADMA levels or increase $\mathrm{NO}_{\mathrm{x}}$ levels via an oxidation pathway, which could be inhibited by the antioxidant, NAC (Figure 1).

\section{Methods}

Reagents were purchased from Sigma-Aldrich (Sydney, Australia) unless otherwise indicated.

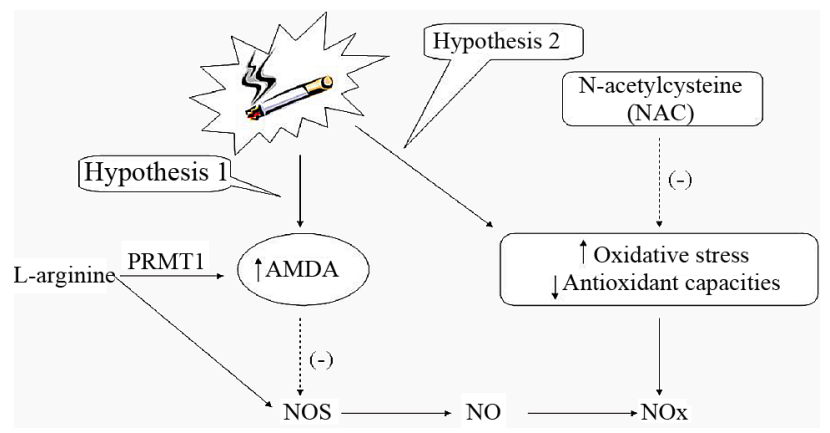

Figure 1. Nitric oxide metabolism pathways and the effects of cigarette smoke. It was hypothesised that CSE would either inhibit NO generation by increasing ADMA levels (Hypothesis 1) or increase $\mathrm{NO}_{\mathrm{x}}$ levels via an oxidation pathways (Hypothesis 2), which could be inhibited by the antioxidant, NAC.

\subsection{Nitrite/Nitrate Assay $\left(\mathrm{NO}_{\mathrm{x}}\right)$}

Total $\mathrm{NO}_{\mathrm{x}}$ concentration in cell media was measured by a fluorescent modification of the Greiss method [36]. Samples were mixed with NADPH, FAD and nitrate reductase with final concentrations of $50 \mu \mathrm{M}, 5 \mu \mathrm{M}$ and 50 IU/L respectively. These were incubated at $37^{\circ} \mathrm{C}$ for 1 hour, which allows nitrate to be converted to nitrite. Nitrite was conjugated with $0.05 \mathrm{mg} / \mathrm{ml} \mathrm{2,3-diaminonaph-}$ thalene (DAN) in $0.62 \mathrm{M} \mathrm{HCL}$ to allow quantification by fluorescence. The reaction was terminated with $2.8 \mathrm{M}$ $\mathrm{NaOH}$. The resultant fluorescence was immediately read on a CytoFluor Series 4000, Multi Well Plate Reader (Perseptive Biosystems, Framingham, MA, USA) at excitation 360/40, emission 395/25, gain 50. The assay limit of detection was $2 \mu \mathrm{mol} / \mathrm{L}$, mean (SD) intra-assay coefficient of variation $3.1(3.4) \%$.

\subsection{ADMA Measurements}

All the samples were aliquoted in $250 \mu \mathrm{L}$ portions and kept at $-70^{\circ} \mathrm{C}$. None of the samples were thawed until processing for the ADMA assay.

ADMA concentrations in cell media were assessed by high performance liquid chromatography (HPLC) $[18,37$, 38]. The chromatography equipment comprised a SCL10A System controller, SIL-10A-XL Auto injector, Sample cooler, LC-10ADVP Liquid Chromatograph and RF10AXL fluorescence detector (Shimadzu, Kyoto, Japan).

ADMA standard concentrations comprised 1.0, 0.5 and $0.1 \mu \mathrm{mol} / \mathrm{L}$ solutions. L-NMMA $(10 \mu \mathrm{mol} / \mathrm{L})$ was added to each standard solution and sample as an internal standard. Standard solution $(200 \mu \mathrm{L})$ or the sample were mixed with $100 \mu \mathrm{L}$ of internal standard and $700 \mu \mathrm{L}$ pH 7.0 phosphate-buffered saline (PBS). These were applied to Oasis MCX solid-phase extraction (SPE) columns (Waters, Rydalmere, Australia) which had been preconditioned with $1 \mathrm{~mL} 100 \%$ methanol and $1 \mathrm{~mL}$ pH 7.0 PBS. The columns were then washed with $1 \mathrm{~mL} 100 \mathrm{mmol} / \mathrm{L}$ 
HCL and $1 \mathrm{~mL} \mathrm{100 \%} \mathrm{methanol.} \mathrm{The} \mathrm{amino} \mathrm{acids} \mathrm{were}$ eluted with $1 \mathrm{~mL}$ elution buffer of ammonia: water: methanol mixture of 10:40:50. The solvent was evaporated under nitrogen at $70^{\circ} \mathrm{C}$. The residue was then dissolved in $100 \mu \mathrm{L}$ mobile phase $\mathrm{A}(0.05 \mathrm{~mol} / \mathrm{L}$ potassium phosphate buffer pH 6.5 with $8.7 \%$ acetonitrile (ACN)), mixed with $100 \mu \mathrm{L}$ ortho-phthaldialdehyde (OPA) containing $0.1 \%$ 3-mercaptopropionic acid. The analytes were separated by a Symmetry C18 $5 \mu \mathrm{m} 3.9 \times 150 \mathrm{~mm}$ column (Waters, Rydalmere, Australia). The height of the peak at 20.5 minutes was used to calculate the ADMA concentration. The coefficient of variation for the standards was $<5 \%$.

\subsection{Cell Culture}

The A549 cell line was cultured in F-12K Medium (Gibco, Grand Island, New York, USA) supplemented with $10 \%$ heat treated fetal bovine serum (FBS) (Gibco, Grand Island, New York, USA), $50 \mathrm{IU} / \mathrm{mL}$ penicillin and streptomycin. $1 \times 10^{6}$ cells were transferred to each flask in $2 \mathrm{~mL}$ medium at the concentration of $0.5 \times 10^{6}$ cells/ $\mathrm{mL}$ one day before the experiment. Viability was assessed by Trypan Blue exclusion.

\subsection{Preparation of the Cigarette Smoke Extract (CSE)}

Main stream smoke from 5 filtered commercial cigarettes (Marlboro, Philip Morris Ltd., Australia) was drawn through $1 \mathrm{~mL}$ of medium by the application of a constant vacuum according to our published method (1). Briefly, each cigarette was burned within 5 to 6 minutes. The $\mathrm{pH}$ of the control and the CSE conditioned medium was titrated to $\mathrm{pH} 7.0$ after being filtered to remove insoluble particles. Control and CSE conditioned medium were further diluted with medium to a control medium and a concentration of $1.0 \% \mathrm{CSE}$ conditioned medium. CSE at a concentration of $1.0 \%$ has been proved to be non-toxic in previous studies and was used within 2 hours of preparation $[1,39]$. Both CSE and control medium were sterilised by filtration using a 0.22 micrometer filter (Millipore, Carrigtwohill, Co. Cork, Ireland).

\subsection{Preparation of NAC Solution}

Thirty minutes prior to the addition of CSE to the medium, NAC 200 mg/mL (Bristol-Myers Squibb, Noble Park North, Victoria, Australia) was added to give a final concentration of $0.8 \mathrm{mM}$.

\subsection{Sampling}

Control medium, 1.0\% CSE, and NAC plus $1.0 \%$ CSE medium were applied to the flasks, respectively. Baseline $\mathrm{NO}_{\mathrm{x}}$ and ADMA levels were measured in all control, $\mathrm{C}$ -
SE and NAC plus CSE media. The supernatant was then sampled at 1hour, 6 hours, 24 hours, 48 hours and 72 hours after incubation. Samples were aliquoted in $250 \mu \mathrm{L}$ portions and kept at $-70^{\circ} \mathrm{C}$. None of the samples were thawed until processing for the assays. Cell concentration and viability were counted at the time of sampling.

\subsection{Statistical Analysis}

Quantitative variables are expressed as mean +/- SE. After confirming the Normal distribution an unpaired Student $t$ test was used for between group comparisons and univariate ANOVA was used for comparisons among three or more groups. Two-tailed $p<0.05$ was regarded as statistically significant.

\section{Results}

\subsection{Cell Viability and Concentration}

No significant differences in the viability of the cells were found between the control media, CSE conditioned media and the NAC pre-treated CSE conditioned media after 72 hours incubation. Mean (SD) cell viability was $95.2(2.3) \%$ in control group, $95.5(2.4) \%$ in the CSE group and $95.6(2.6) \%$ in the NAC pre-treated CSE group from baseline up to 72 hours after incubation. At 72 hours the viability was $96.9 \%$ and $96.6 \%$ for control and CSE groups respectively.

Cell number and concentration in all the groups increased significantly with time $(\mathrm{p}<0.0005)$ while percentage change in cell concentration of CSE exposed cells was significantly lower when compared with both control cells ( $\mathrm{p}=0.004$, univariate analysis) and the cells pretreated with NAC $(p=0.003)$. As the increase in cell number varied, data were expressed as concentration of each marker per million cells.

\section{2. $\mathrm{NO}_{\mathrm{x}}$}

No difference in $\mathrm{NO}_{\mathrm{x}}$ was observed in CSE media compared to control media. Exposure to CSE was associated with an increase in $\mathrm{NO}_{\mathrm{x}}$ over the 72 hours study period which became significantly greater than control at 6hours, 24 hours and 72 hours. Percentage change in $\mathrm{NO}_{\mathrm{x}}$ levels per million cells ( $p<0.0005$, univariate analysis, Figure 2) was significantly higher in the CSE conditioned media compared with the control media. NAC pre-treatment was able to partially reverse the increase in $\mathrm{NO}_{\mathrm{x}}$ levels in response to CSE to a level approaching that seen in the control group ( $\mathrm{p}=0.009$, Figure 2).

\subsection{ADMA}

No consistently detectable ADMA was present in CSE. The addition of CSE to the culture medium demonstrated a significantly greater percentage increase in ADMA me- 
dia levels per million cells when compared with the control media $(p=0.02$, Figure 3$)$. No significant difference was found in ADMA levels between CSE conditioned media and NAC pre-treated CSE media $(p=0.07$, Figure 3).

\subsection{L-Arginine}

L-arginine levels decreased significantly with time in all three groups $(\mathrm{p}<0.0005$, Figure 4$)$, and the percentage

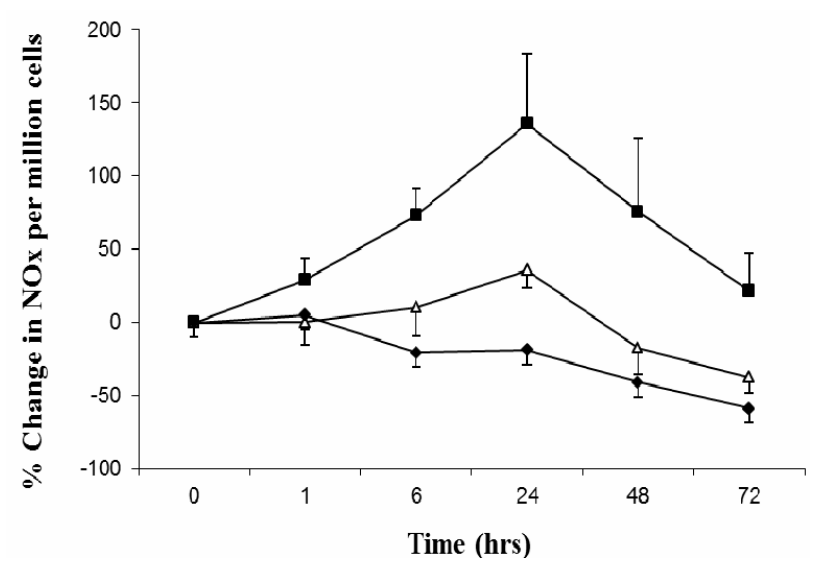

Figure 2. A549 cells were incubated with control medium $(\multimap), 1.0 \%$ CSE conditioned medium ( --$)$ and NAC pre-treated CSE conditioned medium $(\neg-)$. $\mathrm{NO}_{\mathrm{x}}$ levels were measured at baseline, 1hour, 6 hours, 24 hours, 48 hours and 72 hours after incubation. CSE ( --$)$ induced significantly higher $\mathrm{NO}_{\mathrm{x}}$ levels in the conditioned medium when compared with control medium $(\longrightarrow)$ ( $(p<0.0005$, univariate analysis). Significantly lower $\mathrm{NO}_{\mathrm{x}}$ levels were found in the NAC pre-treated CSE conditioned medium $(\neg-)$ when compared with those without NAC pre-treatment as in $2 \mathrm{~A}$ above $(\rightarrow-)(p=0.002$, univariate analysis).

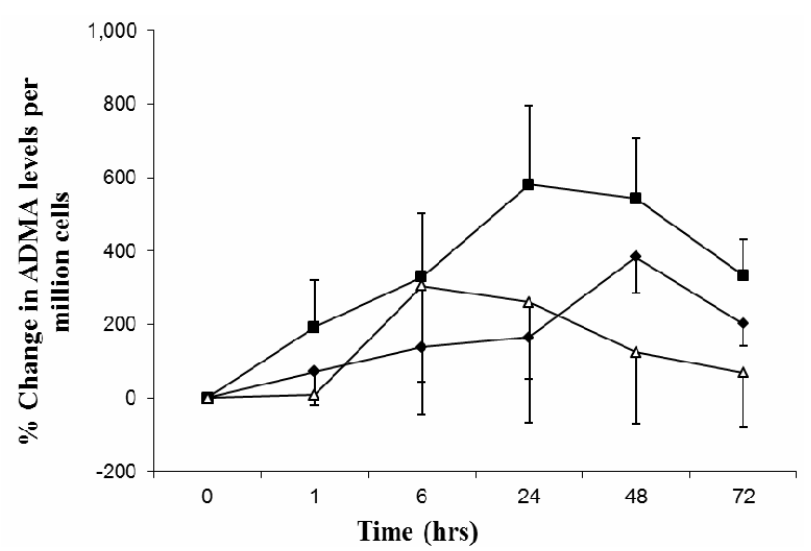

Figure 3. Percentage change in ADMA levels was signifycantly higher in the CSE conditioned medium ( --$)$ compared with the control medium group $(\longrightarrow)(p=0.007$, univariate analysis). No significant difference was observed in ADMA levels between the CSE conditioned medium group $(--)$ and the NAC pre-treated medium cells $(-\Delta)(p=$ 0.07 , univariate analysis).

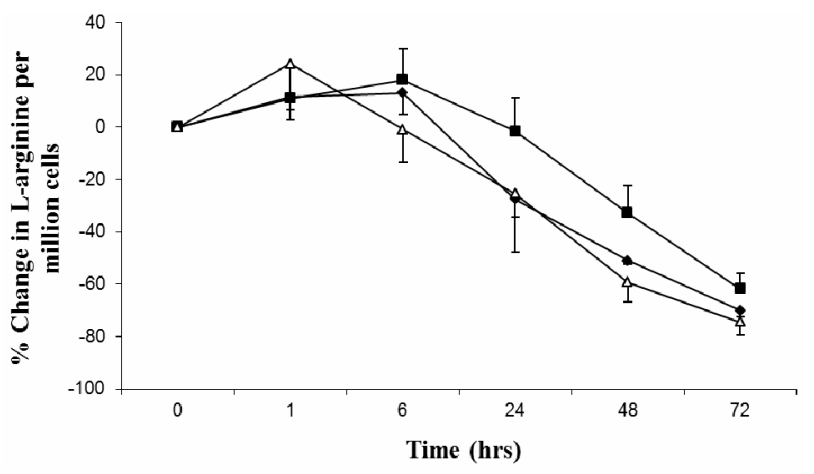

Figure 4. The percentage fall in L-arginine levels in the CSE conditioned medium was significantly less than the control medium $(\multimap)(p=0.04$, univariate analysis). No signifycant difference was found in percentage change in L-arginine levels between the CSE conditioned medium $(\rightarrow-)$ and NAC pre-treated CSE conditioned medium $(-\Delta)(p=$ 0.1 , univariate analysis).

fall in L-arginine levels in CSE conditioned media was significantly less than in the control media $(p=0.04)$ but there was no significant difference in percentage change between CSE conditioned media and NAC pre-treated CSE conditioned media $(\mathrm{p}=0.1)$.

\section{Discussion}

Cigarette smoking is associated with many diseases, including airway inflammation and cardiovascular diseases. It has been demonstrated that smokers have significantly lower exhaled NO levels compared to non-smokers [26], and that either active or passive smoking can decrease exhaled NO levels immediately [27,40].

In these experiments, cell numbers increased after 24 hours incubation in all three groups, but there was slower growth in the cells exposed to CSE conditioned media when compared with control cells, an effect which was reversed by NAC pre-treatment. There was no significant difference in cell viability between the three groups even at 72 hours, but CSS may affect both cell division and the L-arginine pathway.

ADMA has been recognised as an endogenous analogue of L-arginine, and it competitively inhibits NOS [4]. It has been reported that the lung is a major source of circulating ADMA [41]. Type 1 protein-arginine methyltransferases (PRMTs) have been identified to play a key role in arginine methylation to produce ADMA [42] and ADMA is mainly metabolised by the enzyme dimethylarginine dimethylaminohydrolase (DDAH). Increased PRMT levels were observed in hypoxic conditions in a mouse model, which led to elevated ADMA levels [43]. It has been demonstrated that probucol, as a potent antioxidant, is able to decrease ADMA levels by both inhibiting PRMT1 expression and enhancing DDAH activeity [44]. 
In this study, there was an increase in ADMA levels observed in the cell culture medium during the first 24 hours after exposure to CSE, which could explain why exhaled NO levels decrease after acute cigarette smoking in humans. Current smokers in previous studies usually have had a cigarette within 24 hours prior to their exhaled NO sample collection, and the increased ADMA levels in lung epithelial cells during the first 24 hours after cigarette smoke exposure could therefore explain the lower exhaled NO levels observed in current smokers when compared to non-smokers.

The end products of NO were expected to be either decreased in the cells after exposure to CSE as the result of suppressed NO generation via NOS pathway, or could be increased via an oxidative stress pathway. Finding higher $\mathrm{NO}_{\mathrm{x}}$ levels in the CSE conditioned media compared with control media is, however consistent with in vivo studies, which showed increased $\mathrm{NO}_{\mathrm{x}}$ levels in $\mathrm{EBC}$ and plasma samples in healthy smokers when compared with healthy non-smokers $[25,45]$. The increased $\mathrm{NO}_{\mathrm{x}}$ levels in CSE conditioned media or EBC after exposure to cigarette smoke may be due to activation of an oxidative stress pathway. The baseline $\mathrm{NO}_{\mathrm{x}}$ levels in CSE conditioned media were not higher when compared with control media, thus, the elevated $\mathrm{NO}_{\mathrm{x}}$ levels in the CSE conditioned media were not due to $\mathrm{NO}_{\mathrm{x}}$-rich cigarette smoke itself, and the dilution of the CSE was such that any contribution of CSE-donated $\mathrm{NO}_{\mathrm{x}}$ was negligible.

The elevated $\mathrm{NO}_{\mathrm{x}}$ levels in the cell culture medium of cells exposed to CSE were significantly reversed by NAC pre-treatment and could be the result of a decrease in oxidative stress induced by NAC. The protective effect of NAC in airway epithelial cells against cigarette smoke is consistent with a similar finding in our previous study [1]. NAC, with its anti-oxidant properties, can both increase the levels of reduced glutathione (GSH) and act as a direct scavenger of free radicals such as $\mathrm{OH}, \mathrm{H}_{2} \mathrm{O}_{2}$ and $\mathrm{O}_{2}$ [46-48]. Elevated GSH levels have been shown to be correlated with decreased NO levels [49-51]. NAC has been demonstrated to have a protective effect against oxidative stress, which is related to its inhibitory effect on NO production in rat models of diabetes [52,53]. The mechanism of the inhibitory effect of NAC on NO production is not completely understood. One study, however, showed that NAC had strong inhibitory effect on iNOS expression, which led to decreased $\mathrm{NO}_{\mathrm{x}}$ production [54].

In this study, the CSE conditioned media was associated with significantly increased ADMA levels when compared with control media. This is consistent with other studies [55]. No difference, however, was found between CSE conditioned media and NAC pre-treated CSE conditioned media, which suggests NAC is not affecting the ADMA pathway. The fall in L-arginine levels in the
CSE conditioned media was significantly less than that in the control media and there was no significant difference in L-arginine levels between CSE conditioned media and NAC pre-treated CSE media. The reason why cells exposed to CSE consumed less L-arginine but produced more ADMA is unclear. Besides being converted to ADMA via PRMT, L-arginine is also the substrate for NOS to form NO and L-citrulline. In addition, L-arginine is also converted to L-ornithine via the arginase pathway. No studies have reported the effect of CSE on PRMT. Since increased ADMA levels were observed in the CSE conditioned media, more L-arginine would be expected to be converted to ADMA in the CSE exposed cells. Thus, either NOS activity or arginase activity was hypothesised to be inhibited by the CSE. Arginase activity, however, has been reported to be increased by cigarette smoking in asthmatic airways, which leads to more Larginine consumption [56,57]. C, the metabolism of Larginine to both ADMA and L-ornithine might be expected. Consequently, more L-arginine would be consumed in the metabolism from L-arginine to L-ornithine. However, the NOS activity may be inhibited by elevated levels of ADMA in the CSE conditioned media and this would be consistent with a recent report that cigarette smoke extract inhibits NOS activity in a healthy male rabbit model [57].

The decreased consumption of L-arginine and elevated ADMA levels after exposure to CSE were not reversed by NAC pre-treatment. In this in vitro study, CSE did show some effects on ADMA-NOS pathway although the elevated $\mathrm{NO}_{\mathrm{x}}$ levels induced by CSE were mainly due to the activation of oxidative stress rather than the ADMA pathway. Thus, this study has shown that while cigarette smoke in vitro does increase ADMA generation, there is an associated increase in $\mathrm{NO}_{\mathrm{x}}$ via an oxidative stress pathway.

This study has confirmed in vitro the effects seen in the airway in vivo, namely an increase in $\mathrm{NO}_{\mathrm{x}}$, which is not derived directly from cigarette smoke but is a response of airway cells to the smoke. Our hypothesis that an increase in $\mathrm{NO}_{\mathrm{x}}$ may cause a negative feedback inhibition of NOS is not substantiated, as we have shown that there is an increase in ADMA in response to CSE. This increase in ADMA is probably the mechanism by which NOS inhibition occurs.

\section{REFERENCES}

[1] X. M. Wei, H. S. Kim, R. K. Kumar, G. J. Heywood, J. E. Hunt, H. P. McNeil, et al., "Effects of Cigarette Smoke Degranulation and on Production by Mast Cells and Epithelial Cells," Respiratory Research, Vol. 6, No. 1, 2005, pp. 108-112. doi:10.1186/1465-9921-6-108.

[2] J. B. Hibbs, Z. Vavrin Jr. and R. R. Taintor, "L-Arginine Is Required for Expression of the Activated Macrophage 
Effector Mechanism Causing Selective Metabolic Inhibition in Target Cells," Journal of Immunology, Vol. 138, No. 2, 1987, pp. 550-565.

[3] D. D. Rees, R. M. Palmer and S. Moncada, "Role of Endothelium-Derived Nitric Oxide in the Regulation of Blood Pressure," Proceedings of the National Academy of Sciences of the United States of America, Vol. 86, No. 3, 1989, pp. 3375-3378. doi:10.1073/pnas.86.9.3375.

[4] P. Vallance, A. Leone, A. Calver, J. Collier and S. Moncada, "Accumulation of an Endogenous Inhibitor of Nitric Oxide Synthesis in Chronic Renal Failure," The Lancet, Vol. 339, No. 8793, 1992, pp. 572-575. doi:10.1016/0140-6736(92)90865-Z

[5] R. M. Palmer, D. S. Ashton and S. Moncada, "Vascular Endothelial Cells Synthesise Nitric Oxide from L-Arginine," Nature, Vol. 333, No. 6174, 1988, pp. 664-666. doi:10.1038/333664a0.

[6] J. G. Umans, "Less Nitric Oxide, More Pressure, or the Converse?" Lancet, Vol. 349, No. 9055, 1997, pp. 816817. doi:10.1016/S0140-6736(97)22012-X.

[7] J. P. Cooke, "Does ADMA Cause Endothelial Dysfunction?" Arteriosclerosis, Thrombosis, and Vascular Biology, Vol. 20, No. 9, 2000, pp. 2032-2037. doi:10.1161/01.ATV.20.9.2032

[8] Y. Kakimoto and S. Akazawa, "Isolation and Identification of N-G, N-G-and N-G, N'-G-Dimethyl-Arginine, N-Epsilon-Mono-, di-, and Trimethyllysine, and GlucoSylgalactosyl- and Galactosyl-Delta-Hydroxylysine from Human Urine," Journal of Biological Chemistry, Vol. 245, No. 21, 1970, pp. 5751-5758.

[9] H. Matsuoka, S. Itoh, M. Kimoto, K. Kohno, O. Tamai, Y. Wada, et al. "Asymmetrical Dimethylarginine, an Endogenous Nitric Oxide Synthase Inhibitor, in Experimental Hypertension," Hypertension, Vol. 29, 1997, pp. 242-247.

[10] N. Fujiwara, T. Osanai, T. Kamada, T. Katoh, K. Takahashi and K. Okumura, "Study on the Relationship between Plasma Nitrite and Nitrate Level and Salt Sensitivity in Human Hypertension: Modulation of Nitric Oxide Synthesis by Salt Intake," Circulation, Vol. 101, No. 8, 2000, pp. 856-861.

[11] L. J. Millatt, G. S. Whitely, D. Li, J. M. Leiper, H. M. Siragy, R. M. Carey, et al., "Evidence for Dysregulation of Dimethylarginine Dimethylaminohydrolase I in Chronic Hypoxia - induced Pulmonary Hypertension," Circulation, Vol. 108, No. 12, 2003, pp. 1493-1498. doi:10.1161/01.CIR.0000089087.25930.FF

[12] Q. Feng, X. Lu, A. J. Fortin, A. Pettersson, T. Hedner, R. L. Kline, et al., "Elevation of an Endogenous Inhibitor of Nitric Oxide Synthesis in Experimental Congestive Heart Failure," Cardiovascular Research, Vol. 37, No. 3, 1998, pp. 667-675. doi:10.1016/S0008-6363(97)00242-3

[13] M. Usui, H. Matsuoka, H. Miyazaki, S. Ueda, S. Okuda and T. Imaizumi, "Increased Endogenous Nitric Oxide Synthase Inhibitor in Patients with Congestive Heart Failure," Life Sciences, Vol. 62, No. 26, 1998, pp. 2425-2430. doi:10.1016/S0024-3205(98)00225-2

[14] V. P. Valkonen, J. Laakso, H. Paiva, T. Lehtimaki, T. A.
Lakka, M. Isomustajärvi et al., "Asymmetrical Dimethylarginine (ADMA) and Risk of Acute Coronary Events. Does Statin Treatment Influence Plasma ADMA Levels?" Atherosclerosis Supplements, Vol. 4, No. 4, 2003, pp. 19-22. doi:10.1016/S1567-5688(03)00029-1

[15] J. H. Yoo and S. C. Lee, "Elevated Levels of Plasma Homocyst(e)ine and Asymmetric Dimethylarginine in Elderly Patients with Stroke," Atherosclerosis, Vol. 158, No. 2, 2001, pp. 425-30. doi:10.1016/S0021-9150(01)00444-0

[16] P. Lluch, B. Torondel, P. Medina, G. Segarra, J. A. Del Olmo, M. A. Serra, et al. "Plasma Concentrations of Nitric Oxide and Asymmetric Dimethylarginine in Human Alcoholic Cirrhosis," Journal of Hepatology, Vol. 41, No. 1, 2004, pp. 55-59. doi:10.1016/j.jhep.2004.03.016

[17] M. L. Selley, "Increased Concentrations of Homocysteine and Asymmetric Dimethylarginine and Decreased Concentrations of Nitric Oxide in the Plasma of Patients with Alzheimer's Disease," Neurobiology of Aging, Vol. 24, No. 7, 2003, pp. 903-907.

doi:10.1016/S0197-4580(03)00007-1

[18] J. Wang, A. S. Sim, X. L. Wang, C. Salonikas, D. Naidoo and D. E. Wilcken, "Relations between Plasma Asymmetric Dimethylarginine (ADMA) and Risk Factors for Coronary Disease," Atherosclerosis, Vol. 184, No. 2, 2006, pp. 383-388. doi:10.1016/j.atherosclerosis.2005.05.002

[19] H. M. Eid, H. Arnesen, E. M. Hjerkinn, T. Lyberg and I. Seljeflot, "Relationship between Obesity, Smoking, and the Endogenous Nitric Oxide Synthase Inhibitor, Asymmetric Dimethylarginine," Metabolism, Vol. 53, No. 12, 2004, pp. 1574-1579.

doi:10.1016/j.metabol.2004.06.026

[20] S. A. Kharitonov, D. Yates, R. A. Robbins, R. LoganSinclair, E. A. Shinebourne and P. J. Barnes, "Increased Nitric Oxide in Exhaled Air of Asthmatic Patients," Lancet, Vol. 343, No. 8890, 1994, pp. 133-135. doi:10.1016/S0140-6736(94)90931-8

[21] D. H. Yates, S. A. Kharitonov, R. A. Robbins, P. S. Thomas and P. J. Barnes, "Effect of a Nitric Oxide Synthase Inhibitor and a Glucocorticosteroid on Exhaled Nitric Oxide," American Journal of Respiratory and Critical Care Medicine, Vol. 152, No. 3, 1995, pp. 892-896.

[22] K. Ganas, S. Loukides, G. Papatheodorou, P. Panagou and N. Kalogeropoulos, "Total Nitrite/Nitrate in Expired Breath Condensate of Patients with Asthma," Respirology Medicine, Vol. 95, No. 8, 2001, pp. 649-654. doi:10.1053/rmed.2001.1117

[23] M. Corradi, A. Pesci, R. Casana, R. Alinovi, M. Goldoni, M. V. Vettori, et al., "Nitrate in Exhaled Breath Condensate of Patients with Different Airway Diseases," Nitric Oxide, Vol. 8, No. 1, 2003, pp. 26-30. doi:10.1016/S1089-8603(02)00128-3

[24] B. Balint, L. E. Donnelly, T. Hanazawa, S. A. Kharitonov and P. J. Barnes, "Increased Nitric Oxide Metabolites in Exhaled Breath Condensate after Exposure to Tobacco Smoke," Thorax, Vol. 56, No. 6, 2001, pp. 456-461. doi:10.1136/thorax.56.6.456 
[25] J. Liu and P. S. Thomas, "Cigarette Smoking Increases Nitrite/Nitrate in Exhaled Breath Condensate," Respirology, Vol. 9, 2004, p. A40.

[26] S. A. Kharitonov, R. A. Robbins, D. Yates, V. Keatings and P. J. Barnes, "Acute and Chronic Effects of Cigarette Smoking on Exhaled Nitric Oxide," American Journal of Respiratory and Critical Care Medicine, Vol. 152, No. 2, 1995, pp. 609-612.

[27] D. H. Yates, H. Breen and P. S. Thomas, "Passive Smoke Inhalation Decreases Exhaled Nitric Oxide in Normal Subjects," American Journal of Respiratory and Critical Care Medicine, Vol. 164, No. 6, 2001, pp. 1043-1046.

[28] T. Tokimoto and K. Shinagawa, "Nitric Oxide Generation in Aqueous Solutions of Cigarette Smoke and Approaches to its Origin," Biological Chemistry, Vol. 382, No. 11, 2001, pp. 1613-1619. doi:10.1515/BC.2001.196

[29] R. A. Robbins, P. J. Barnes, D. R. Springall, J. B. Warren, O. J. Kwon, L. D. Buttery, et al., "Expression of Inducible Nitric Oxide in Human Lung Epithelial Cells," Biochemical and Biophysical Research Communications, Vol. 203, No. 1, 1994, pp. 209-218. doi:10.1006/bbrc.1994.2169

[30] P. R. Mills, R. J. Davies and J. L. Devalia, "Airway Epithelial Cells, Cytokines, and Pollutants," American Journal of Respiratory and Critical Care Medicine, Vol. 160, 1999, pp. S38-S43.

[31] Anonymous, "N-Acetylcysteine," Alternative Medicine Review, Vol. 5, No. 5, 2000, pp. 467-471.

[32] N. van Zandwijk, "N-Acetylcysteine (NAC) and Glutathione (GSH): Antioxidant and Chemopreventive Properties, with Special Reference to Lung Cancer," Journal of Cellular Biochemistry, Vol. 59, No. S22, 1995, pp. 24-32. doi: $10.1002 / \mathrm{jcb} .240590805$

[33] G. S. Kelly, "Clinical Applications of N-Acetylcysteine," Alternative Medicine Review, Vol. 3, No. 2, 1998, pp. 114-127.

[34] D. F. Rogers and P. K. Jeffery, "Inhibition by Oral $\mathrm{N}$-acetylcysteine of Cigarette Smoke-Induced "Bronchitis" in the Rat," Experimental Lung Research, Vol. 10, No. 3, 1986, pp. 267-283. doi:10.3109/01902148609061497

[35] R. B. Balansky, F. D'Agostini, P. Zanacchi and S. De Flora. "Protection by N-Acetylcysteine of the Histopathological and Cytogenetical Damage Produced by Exposure of Rats to Cigarette Smoke," Cancer Letters, Vol. 64, No. 2, 1992, pp. 123-131. doi:10.1016/0304-3835(92)90072-4

[36] T. P. Misko, R. J. Schilling, D. Salvemini, W. M. Moore and M. G. Currie, "A Fluorometric Assay for the Measurement of Nitrite in Biological Samples," Analytical Biochemistry, Vol. 214, No. 1, 1993, pp. 11-16. doi:10.1006/abio.1993.1449

[37] T. Teerlink, R. J. Nijveldt, S. de Jong and P. A. M. van Leeuwen, "Determination of Arginine, Asymmetric Dimethylarginine, and Symmetric Dimethylarginine in $\mathrm{Hu}-$ man Plasma and Other Biological Samples by High-Performance Liquid Chromatography," Analytical Biochemistry, Vol. 303, No. 2, 2002, pp. 131-137. doi:10.1006/abio.2001.5575

[38] R. Schnabel, S. Blankenberg, E. Lubos, K. J. Lackner, H. J. Rupprecht, C. Espinola-Klein, et al., "Asymmetric Dimethylarginine and the Risk of Cardiovascular Events and Death in Patients with Coronary Artery Disease: Results from the AtheroGene Study," Circulation Research, Vol. 97, No. 5, 2005, pp. e53-e59. doi:10.1161/01.RES.0000181286.44222.61

[39] P. S. Thomas, R. E. Schreck and S. C. Lazarus, "Tobacco Smoke Releases Performed Mediators from Canine Mast Cells and Modulates Prostaglandin Production," American Journal of Physiology, Vol. 263, No. 1, 1992, pp. L67-L72.

[40] M. Maniscalco, V. Di Mauro, E. Farinaro, L. Carratu and M. Sofia, "Transient Decrease of Exhaled Nitric Oxide after Acute Exposure to Passive Smoke in Healthy Subjects," Archives of Environmental Health, Vol. 57, No. 5, 2002, pp. 437-440. doi:10.1080/00039890209601434

[41] P. Bulau, D. Zakrzewicz, K. Kitowska, J. Leiper, A. Gunther, F. Grimminger, et al., "Analysis of Methylarginine Metabolism in the Cardiovascular System Identifies the Lung as a Major Source of ADMA," American Journal of Physiology - Lung Cellular and Molecular Biology, Vol. 292, No. 1, 2007, pp. L18-L24. doi:10.1152/ajplung.00076.2006

[42] W. K. Paik and S. Kim, "Protein Methylase I. Purification and Properties of the Enzyme," Journal of Biological Chemistry, Vol. 243, No. 9, 1968, pp. 2108-2114.

[43] A. O. Yildirim, P. Bulau, D. Zakrzewicz, K. E. Kitowska, N. Weissmann, F. Grimminger, et al., "Increased Protein Arginine Methylation in Chronic Hypoxia: Role of Protein Arginine Methyltransferases," American Journal of Respiratory Cell and Molecular Biology, Vol. 35, No. 4, 2006, pp. 436-443. doi:10.1165/rcmb.2006-0097OC

[44] J. L. Jiang, X. H. Zhang, N. S. Li, W. Q. Rang, Y. Feng, C. P. Hu, et al., "Probucol Decreases Asymmetrical Dimethylarginine Level by Alternation of Protein Arginine Methyltransferase I and Dimethylarginine Dimethylaminohydrolase Activity," Cardiovascular Drugs and Therapy, Vol. 20, No. 4, 2006, pp. 281-294. doi:10.1007/s10557-006-9065-1

[45] J. Liu, A. Sandrini, M. C. Thurston, D. H. Yates and P. S. Thomas, "Nitric Oxide and Exhaled Breath Nitrite/Nitrates in Chronic Obstructive Pulmonary Disease Patients," Respiration, Vol. 74, No. 6, 2007, pp. 617-623. doi: $10.1159 / 000106379$

[46] O. I. Aruoma, B. Halliwell, B. M. Hoey and J. Butler, "The Antioxidant Action of N-Acetylcysteine: Its Reaction with Hydrogen Peroxide, Hydroxyl Radical, Super oxide, and Hypochlorous Acid," Free Radical Biology and Medicine, Vol. 6, No. 6, 1989, pp. 593-597. doi:10.1016/0891-5849(89)90066-X

[47] M. Benrahmoune, P. Therond and Z. Abedinzadeh, "The Reaction of Superoxide Radical with N-Acetylcysteine," Free Radical Biology and Medicine, Vol. 29, No. 8, 2000, pp. 775-782. doi:10.1016/S0891-5849(00)00380-4

[48] A. M. Sadowska, B. Manuel-y-Keenoy and W. A. De Backer, "Antioxidant and Anti-Inflammatory Efficacy of NAC in the Treatment of COPD: Discordant in Vitro and 
in vivo Dose-Effects: A Review," Pulmonary Pharmacology \& Therapeutics, Vol. 20, No. 1, 2007, pp. 9-22. doi:10.1016/j.pupt.2005.12.007

[49] K. Husain, C. Whitworth, S. M. Somani and L. P. Rybak, "Carboplatin-induced Oxidative Stress in Rat Cochlea," Hearing Research, Vol. 159, No. 1-2, 2001, pp. 14-22. doi:10.1016/S0378-5955(01)00306-9

[50] K. Prabhakaran, L. Li, J. L. Borowitz and G. E. Isom, "Inducible Nitric Oxide Synthase Up-Regulation and Mitochondrial Glutathione Depletion Mediate Cyanide-Induced Necrosis in Mesencephalic Cells," Journal of Neuroscience Research, Vol. 84, No. 5, 2006, pp. 1003-1011. doi:10.1002/jnr.20998

[51] S. Payabvash, M. H. Ghahremani, A. Goliaei, A. Mandegary, H. Shafaroodi, M. Amanlou, et al., "Nitric Oxide Modulates Glutathione Synthesis During Endotoxemia," Free Radical Biology and Medicine, Vol. 41, No. 12, 2006, pp. 1817-1828. doi:10.1016/j.freeradbiomed.2006.09.010

[52] E. Okur, M. Kilinc, I. Yildirim, M. A. Kilic and F. I. Tolun, "Effect of N-Acetylcysteine on Carboplatin-Induced Ototoxicity and Nitric Oxide Levels in a Rat Model," Laryngoscope, Vol. 117, No. 12, 2007, pp. 2183-2186. doi:10.1097/MLG.0b013e31813e6041

[53] Z. Xia, P. R. Nagareddy, Z. Guo, W. Zhang and J. H. McNeill, "Antioxidant-N-Acetylcysteine Restores Systemic Nitric Oxide Availability and Corrects Depressions in Arterial Blood Pressure and Heart Rate in Diabetic Rats," Free Radical Research, Vol. 40, No. 2, 2006, pp. 175-184. doi:10.1080/10715760500484336

[54] S. Bergamini, C. Rota, R. Canali, M. Staffieri, F. Daneri, A. Bini, et al., "N-Acetylcysteine Inhibits In Vivo Nitric Oxide Production by Inducible Nitric Oxide Synthase," Nitric Oxide, Vol. 5, No. 4, 2001, pp. 349-360. doi:10.1006/niox.2001.0356

[55] W. Z. Zhang, K. Venardos, J. Chin-Dusting and D. M. Kaye, "Adverse Effects of Cigarette Smoke on NO Bioavailability. Role of Arginine Metabolism and Oxidative Stress," Hypertension, Vol. 48, No. 2, 2006, pp. 278-285. doi:10.1161/01.HYP.0000231509.27406.42

[56] C. Bergeron, L. P. Boulet, N. Page, M. Laviolette, N. Zimmermann, M. E. Rothenberg, et al., "Influence of Cigarette Smoke on the Arginine Pathway in Asthmatic Airways: Increased Expression of Arginase I," Journal of Allergy and Clinical Immunology, Vol. 119, No. 2, 2007, pp. 391-397. doi:10.1016/j.jaci.2006.10.030

[57] M. Imamura, Y. Waseda, G. V. Marinova, T. Ishibashi, S. Obayashi, A. Sasaki, et al., "Alterations of NOS, Arginase and DDAH Proteins Expression in the Rabbit Cavernous Tissue Following Administration of Cigarette Smoke Extract," American Journal of Physiology-Regulatory, Integrative and Comparative Physiology, Vol. 293, No. 5, 2007, pp. R2081-R2089. doi:10.1152/ajpregu.00406.2007 